\title{
The Communicable Disease Centre and Challenges in Infectious Disease Management in Singapore
}

\author{
Kymelya Sari Mohammad Raji, ${ }^{1} M S c$, Li Yang $\underline{\operatorname{Hsu}},{ }^{1} M B B S$, MPH, Kah Seng Loh, ${ }^{2,3}{ }_{P h D}$
}

In December 2018, the historic Communicable Disease Centre (CDC) - formerly Middleton Hospital from 1920 to 1985 - ceased operations to make way for the state-of-the-art National Centre for Infectious Diseases (NCID), a much larger facility that holds 330 beds. At the launch of NCID in September 2019, the Health Minister of Singapore, Gan Kim Yong, in his speech hailed CDC's "critical role for well over a century in combating outbreaks in Singapore". ${ }^{1}$

The long and eventful history of CDC provides key insights into a long-standing issue that is central to infectious disease management in Singapore: need versus cost. While it is important to have an infectious diseases hospital that is capable of dealing with major outbreaks, its establishment and maintenance are nevertheless an expensive undertaking. The issue of building or developing an infectious diseases hospital in Singapore can be viewed through the lens of 3 key historical and developmental milestones: 1) debate on an infectious disease hospital from the late $19^{\text {th }}$ Century to the founding of CDC in 1913;2) expansion of medical services in Singapore after the Second World War into the 1950s; and 3) emergence of new infectious diseases from the 1990s to the development of NCID.

In the 1890 s, the need for a proper medical facility to deal with infectious disease cases in Singapore was clear. Europeans and Eurasians were treated at the General Hospital but the Asians-who formed the majority of patients - had only recourse to an inadequate and poorly outfitted facility located along Balestier Road. In fact, most Asian patients-particularly men with higher income, women and children - shunned the latter for "fear of injury" to themselves. ${ }^{2}$ Not surprisingly, attempts to control infectious diseases-particularly the dangerous trio of notifiable illnesses, namely bubonic plague, cholera and smallpox - were often unsuccessful as Asians failed to notify the colonial authorities of cases or to seek treatment in a hospital.
The establishment of CDC was a long and protracted process. This was because the Straits Settlements government and the Singapore Municipal Commission did not want to assume responsibility for the cost and building of CDC, even though it fell within their purview to do so and most infectious disease cases were traced to urban centres. The matter was constantly tossed to and fro between them: the government argued that it had committed much of its budget to military spending while the Commission insisted that its priority lied with the provision of clean water supply and proper sanitation facilities in the Municipality.

In 1899, after their inspection of the Balestier Road facility, the principal civil medical officer and colonial engineer reported that it was running satisfactorily. Their report, however, was rejected by the municipal health officer, Dr WRC Middleton, who insisted that the walls and floors of the facility were "impregnated with the germs of diseases treated there". ${ }^{3}$ However, the governor of the Straits Settlements, Charles Mitchell, deferred the matter and ruled that "it is not desirable to erect a superior class of hospital for infectious diseases at Balestier Road." 3 Despite this setback, Dr Middleton continued to press the issue and in 1907, the colonial government passed Municipal Ordinance XXXVII which broadened the purview of the Commission to include prevention and suppression of dangerous, infectious illnesses in the town precincts.

Although the ordinance provided the legislative basis for the establishment of a new infectious diseases hospital, it was delayed by social resistance against the site of the facility. Several sites were considered and rejected. For example, various reasons were reported by the Singapore Free Press against a proposed site in Paya Lebar; they included proximity to an expanding village, spreading of infections by flies and mosquitos and presence of a hospital would cause real estate prices to plummet. For financial and health reasons, residents

\footnotetext{
'Saw Swee Hock School of Public Health, National University of Singapore, Singapore

${ }^{2}$ Chronicles Research \& Education Pte Ltd, Singapore

${ }^{3}$ School of Social Sciences, University of Western Australia, Australia

Address for Correspondence: A/Prof Hsu Li Yang, Saw Swee Hock School of Public Health, National University of Singapore, 12 Science Drive 2 , Tahir Foundation Building, \#10-01, Singapore 117549.

Email: mdchly@nus.edu.sg
} 
did not want an infectious diseases hospital that was sited in close proximity to their homes. ${ }^{4}$ Eventually, the Commissioners settled on a 25 -acre site at Moulmein Road which was located close to the existing facility along Balestier Road.

By this time, however, the building programme had become much more modest than originally envisaged. In 1910, the municipality alleged that the project had been "condemned as extravagant by the Government and a curtailed scheme proposed instead". ${ }^{5}$ It was not until September 1910 when both parties agreed on a diminished scheme that would cater to all infectious disease patients regardless of social class and ethnicity. In 1911, construction of the new hospital finally began.

When the hospital opened in mid-1913 (Fig. 1), it continued to segregate European and Eurasian patients from Asians, and there were also different classes of patients. The hospital comprised 3 sections for bubonic plague, cholera and smallpox. In the smallpox section - the only one that was completed according to the original scheme-there were separate wards for Asians and Europeans and different ward classes (Classes A and B) for Asian patients. With a smaller budget, it also meant the bubonic plague and cholera sections had only Class B and lower wards; however, European, Eurasian and upper-class Asian patients still enjoyed superior accommodation in the 2-bedded observation and discharge wards.

However, it did not take the colonial government long to realise its mistake in seeking fiscal prudence. The notifiable diseases turned out to be rare, but the 172 beds in the new hospital were grossly inadequate after new

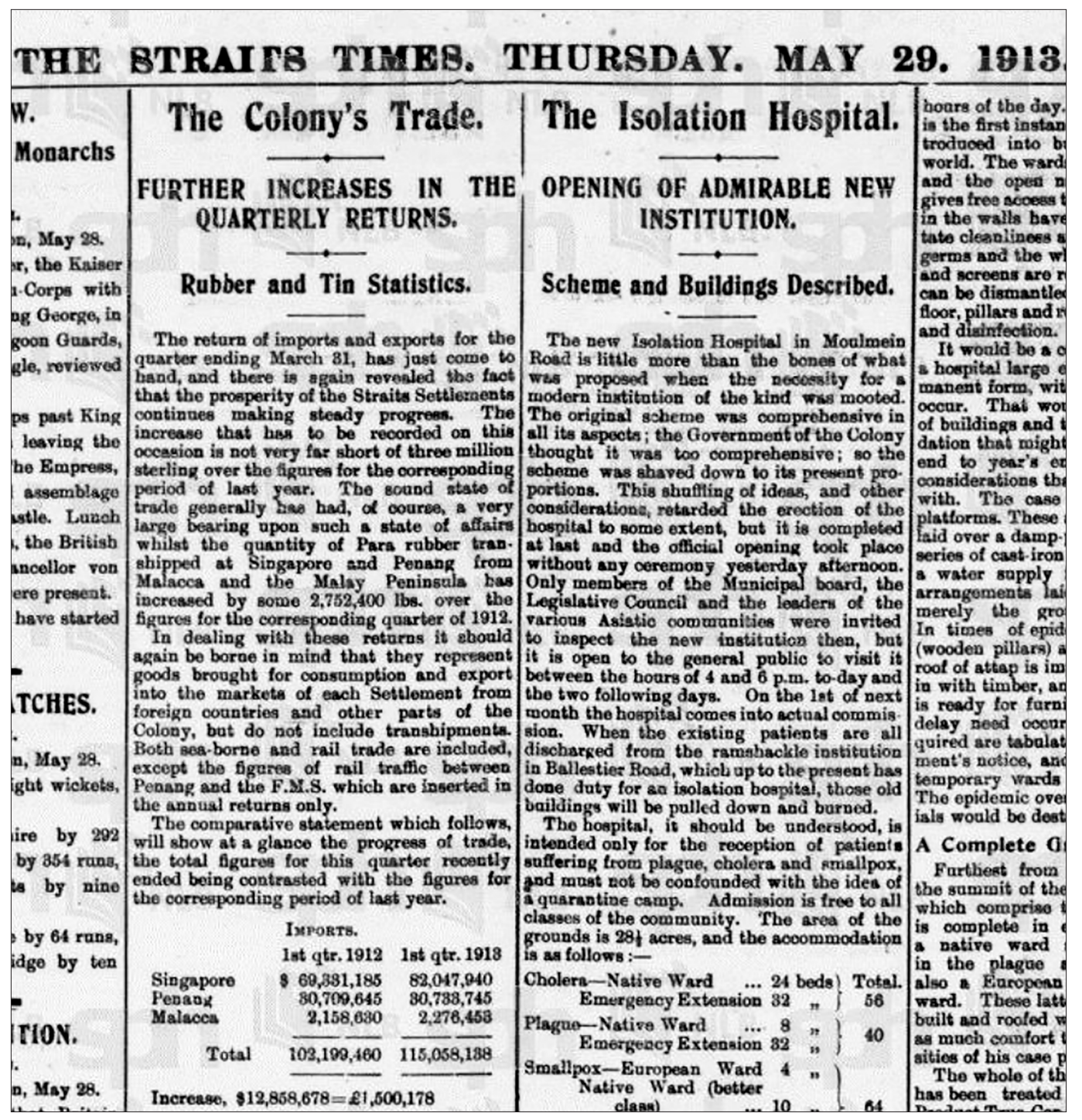

Fig. 1. Newspaper report on the opening of the new infectious diseases hospital at Moulmein Road in 1913. Source: The Straits Times ${ }^{C}$ Singapore Press Holdings Limited. 
infections became more common in Singapore including diphtheria, chicken pox and puerperal fever (both made notifiable in 1916), cerebrospinal fever (notifiable in 1917) and tuberculosis (notifiable in 1918). The new hospital also could not cope with the outbreak of the deadly global influenza pandemic - in 1918 and 1919in Singapore. In 1919, the Commission was forced to add a ward for diphtheria, a second cholera ward in 1921 and a second bubonic plague ward in 1922. Additionally, accommodation for hospital staff and other facilities were built. After Dr Middleton-who had pushed for these expansion works - retired from the municipality in 1920, the hospital was aptly named after him.

At the end of the Second World War, questions over the role and development of Middleton Hospital resurfaced. The debate took the form of 2 key questions: would Singapore need a second infectious disease hospital, and which agency should manage Middleton Hospital? Both were raised in proposals for a 10 -year Medical Plan for Singapore in 1947, an ambitious undertaking by the British colonial government as it attempted to improve health and medical services for the general population. The Plan had sought to remedy the neglect of medical services under the Japanese Occupation and to restore them to standards enjoyed by the population before the war. As it turned out, however, those proposals would, in fact, exceed those standards. This was evident from the initial proposals outlined in the Plan to build a new 50-bed infectious diseases hospital to treat major infectious diseases beyond municipal limits, as well as to increase staff numbers and upgrade the facilities in Middleton Hospital. ${ }^{6}$

Unfortunately, the Medical Plan was met with strong opposition, partly because of its prohibitive cost. When the final-but scaled down-version was announced in 1948 , the proposals that pertained to infectious disease management were removed and deferred to a committee. As was the case with the founding of $\mathrm{CDC}$, financial considerations were an overwhelming factor. The infectious disease committee was mindful of the issue when, in April 1950, it noted that "To keep a large staff for a hospital in which the bedstate was bound to fluctuate widely was uneconomic while in epidemics 'demands' would have to be made on Government". ${ }^{7}$ Earlier, in February of the same year, the medical superintendent of Middleton Hospital, Dr Ng See Yook, had submitted a memorandum to the municipal health officer. In it, he stated that with Middleton Hospital, it was "futile" to build a second hospital and resources should instead be diverted to improve the existing hospital to deal with all infectious diseases throughout Singapore. ${ }^{8}$
Consequently, Middleton Hospital remained the only infectious diseases hospital on the island state. However, only 1 new ward - a 30-bed cubicle wardwas added to the hospital in 1956. Fitted out with selfcontained rooms and a glass partition (the first of its kind in Malaya and Singapore) that enabled nurses to observe patients from other rooms, the cubicle ward was considered groundbreaking with its modern design. Nevertheless, the postwar development of Middleton Hospital was much more modest than the building programme that clouded its first decade of operation. It was considerably more subdued than proposals by the British colonial government to build a 48-bed ward, foundations and services for 2 wards with 24 beds each and 3 small observation wards in 1941, all of which were disrupted by the outbreak of the Second World War. The committee did, however, agreed to take on additional medical and nursing staff for the hospital and to provide accommodation for them. ${ }^{9}$

The events surrounding the development of Middleton Hospital soon took a surprising turn. At the turn of the $20^{\text {th }}$ Century, the Straits Settlement government and the Singapore Municipal Commission were disinterested in running the hospital; now, both parties were clamouring to manage it. Another infectious disease committee, formed in 1951, recommended that the British colonial government assumed full responsibility for Middleton Hospital since it also administered all other hospitals in Singapore. ${ }^{10}$ However, the City Council (successor to the Singapore Municipal Commission after Singapore was redesignated a city from a town in 1951) contended that it should be vested with the authority to do so since it was within its purview to manage infectious diseases. To counter this argument, the British colonial government proposed that the City Council should continue to administer Middleton Hospital, but the Council and itself would have "dual control" of infectious disease management as before. ${ }^{11}$ The matter remained unresolved until 1960 when the City Council was abolished by the government and Middleton Hospital came under the auspices of the Ministry of Health.

By the early 1980s, Middleton Hospital was facing an existential crisis. With mass vaccination campaigns, improved living standards and environmental health control, major infectious diseases-namely bubonic plague, cholera, diphtheria, poliomyelitis and smallpox-had become uncommon. The issue over how the health authorities should manage an independent infectious diseases hospital with a large pool of permanent staff was eventually resolved in 1985 after Middleton Hospital was absorbed into Tan 
Tock Seng Hospital (TTSH). Renamed CDC, it lost its status as a hospital.

That very year, however, the first cases of acquired immune deficiency syndrome (AIDS) were diagnosed in Singapore and CDC was designated the primary institution to treat AIDS inpatients. ${ }^{12}$ Two wards that were formerly used to manage poliomyelitis cases were converted for this purpose. Treatment of this difficult, initially terminal and feared disease heralded an important phase in the history of medicine in Singapore. Prior to the availability of affordable and effective drugs in the late 1990s to treat AIDS, much of the early work with AIDS patients in CDC was limited to segregation, palliative care and counselling.

CDC remained under the purview of the Ministry of Health until 1995, when it came under the administration of TTSH. This legacy has allowed CDC to reap the twin benefits of leveraging on the manpower and operational capacity of TTSH to be efficient, and to continue to receive financial support from the government.

Despite these changes, by the end of the $20^{\text {th }}$ Century the need for a bigger and much improved facility to manage the emerging trend of new infectious diseases had become more urgent than ever. As an ageing institution, $\mathrm{CDC}$ was built on the old pavilion-hospital principle and had inadequate isolation rooms. This became particularly obvious during the outbreak of severe acute respiratory syndrome (SARS) in 2003 when TTSH was designated the SARS inpatient hospital. In its annual reports in 1993 and 1995, the Ministry of Health announced plans for a new CDC that would be ready in 4 to 5 years. However, what followed was a long period of debate and gestation on the issue. In an online interview with the medical director of CDC on 3 July 2019, Dr Suok Kai Chew, he described the situation as follows: "There were several revisions of the redevelopment plans over time since the mid-1990s to take into account the emerging pattern of infectious diseases. This was especially so after the occurrences of the SARS outbreak, Ebola virus infection and bioterrorism. There were extensive discussions, studies and overseas site visits to centres such as the Centers for Disease Control and Prevention in the United States on the types and size of facilities the CDC needed. For example, whether high-level biosafety wards and laboratories, which were expensive to build and maintain, were required for the new CDC. The new NCID was the fruition of all these difficult deliberations."

In an interview with Professor Leo Yee Sin on 10 June 2019, the last clinical director of CDC and executive director of NCID clarified that the closure of Fairfield Infectious Diseases Hospital in Australia in 1996 and the Nipah virus outbreak had lent much weight to the argument for the establishment of a new infectious diseases hospital. These developments, together with the weight of long history of a centralised infectious diseases institution in Singapore, finally cemented the case for a new facility. Unfortunately, the founding of NCID was further delayed by the onset of the 2008 global financial crisis.

History is a guide to the future. Built at a cost of S\$900 million, ${ }^{13}$ NCID was founded on a positive and timely response to current "megatrends in infectious diseases", namely emerging and re-emerging infections, antimicrobial resistance, biotechnological advances and demographic changes in Singapore. ${ }^{14,15}$ Although the impact the new hospital will have in terms of containing large outbreaks - such as an influenza pandemic-is limited, it is anticipated to be at least capable of preventing the outsized impact of a potential future SARS-like outbreak and to provide safe management of highly lethal, imported infections like Ebola. ${ }^{13}$ This is clearly demonstrated after NCID was designated the primary treatment centre in Singapore for the COVID-19 pandemic in early 2020 .

Questions on the role, need and cost of a major facility for infectious disease management that were raised at early major historical milestones of Singapore are likely to be heard again in the distant future. To minimise the need for such a facility, greater investment in other interventions that can prevent or minimise the impact of future outbreaks is needed. These can include expansion of the infrastructure and capacity for outbreak containment in all hospitals, improvement in outbreak detection and response to minimise the scale of future outbreaks and better crisis management at the general population level.

\section{Acknowledgements}

This work was supported by the Heritage Research Grant (HRG026) of the National Heritage Board, Singapore. Any opinions, findings and conclusions or recommendations expressed here are those of the authors and do not necessarily reflect the views of the National Heritage Board, Singapore. The authors would like to thank Sharon Loh, Mok Ly Yng, Isabel Drake, Jasmine Chin, Madeline Gwee, Lim Xin Hwee, Nur'ain Noor Bani, Jillian Colombo, Charmaine Ang and Koh Yan En for their assistance with this work. They also thank the many interviewees who gave of their time and memories, and the agencies and institutions that supported this work in various ways including Tan Tock Seng Hospital, Urban Redevelopment Authority, Singapore Land Authority, National Museum of Singapore and the National Centre for Infectious Diseases. 


\section{REFERENCES}

1. Ministry of Health, Singapore. Speech by Mr Gan Kim Yong, Minister for Health, at the Official Opening of the National Centre for Infectious Diseases on Saturday, 7 September 2019 at the National Centre for Infectious Diseases. Available at: https://www.moh.gov.sg/ news-highlights/details/speech-by-mr-gan-kim-yong-minister-forhealth-at-the-official-opening-of-the-national-centre-for-infectiousdiseases-on-saturday-7-september-2019-at-the-national-centre-forinfectious-diseases. Accessed on 8 January 2020

2. Singapore Municipality. Administration Report of the Singapore Municipality for 1899. Singapore: Straits Printing Office; 1899. p. 104

3. Singapore Municipality. Administration Report of the Singapore Municipality for 1899. Singapore: Straits Printing Office; 1899. p. 106

4. Singapore Free Press and Mercantile Advertiser. Correspondence, 28 June 1907.

5. Singapore Municipality. Administration Report of the Singapore Municipality for 1910. Singapore: Straits Printing Office; 1910. p. 11

6. The Medical Plan for Singapore, 11 February 1947. Advisory Council Paper Number 12 of 1947. Annexure A

7. HD 113/45 Volume 1, Minutes of a Conference held on 25 April 1950 at C.M.O's Office, General Hospital, to discuss the question of staffing Middleton Hospital.
8. HD 113/45 Volume 1, Ng See Yook, Memo to the municipal health officer, 27 February 1950.

9. HD 113/45 Volume 1, Minutes of a Conference held on 29 March 1950 at the Municipal Health Office to discuss the future status of Middleton Hospital.

10. HD 113/45 Volume 2 Number 735/46, Report of the Infectious Disease Committee.

11. HD 113/45 Volume 2, Memo from Director of Medical Services to the Colonial Secretary, 7 October 1952.

12. Chew SK. Trends in human immunodeficiency virus infection: epidemiology in Singapore. Ann Acad Med Singapore 1993;22:142-5.

13. Kurohi R. New centre to bolster Singapore's infectious disease management. The Straits Times, 16 January 2019. Available at: https://www.straitstimes.com/singapore/health/new-centre-tobolster-singapores-infectious-disease-management. Accessed on 8 January 2020.

14. Wong SY, Tan BH. Megatrends in infectious diseases: the next 10 to 15 Years. Ann Acad Med Singapore 2019;48:188-94.

15. Dennis S, Fisher D. Climate change and infectious diseases: the next 50 years. Ann Acad Med Singapore 2018;47:401-4. 